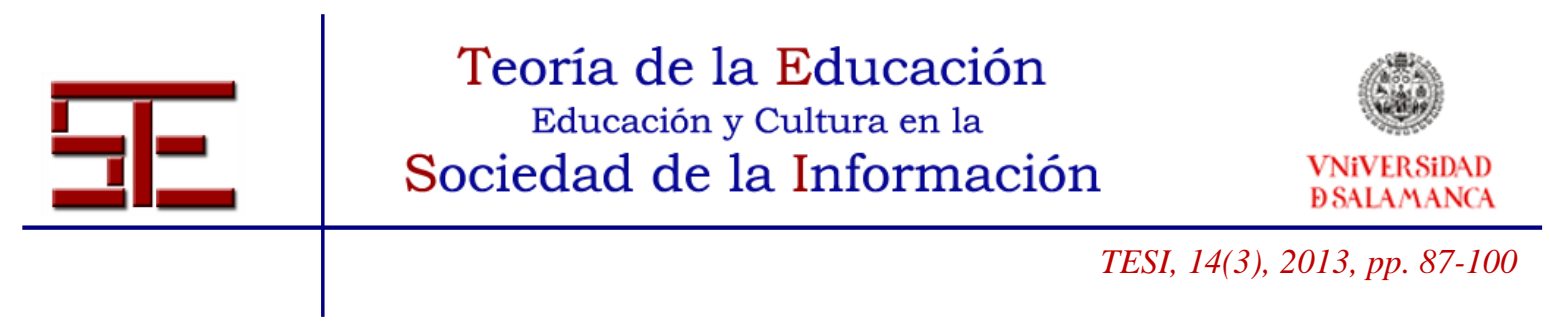

\title{
LA ETICIDAD DE LAS TIC. LAS COMPETENCIAS TRANSVERSALES Y SUS PARADOJAS
}

Resumen: Los sistemas educativos en la era de las nuevas tecnologías conllevan una revolución en los procesos de aprendizaje tradicionales. Para una buena implementación de estos cambios, el profesorado debe formarse en 'nuevas' competencias de carácter ético, que confieren sentido a las competencias digitales, una formación que conlleva una nueva forma de entender la pedagogía: donde los estudiantes adquieren protagonismo y autonomía para obtener, por ellos mismos, respuestas a los interrogantes. Una implementación transversal, en las aulas, de ambas tipologías de competencias nos desvela ciertas paradojas que la educación actual debe asumir como retos de presente y futuro.

Palabras clave: competencia ética; competencias digitales; transversalidad; aprendizaje significativo; agencias de sentido.

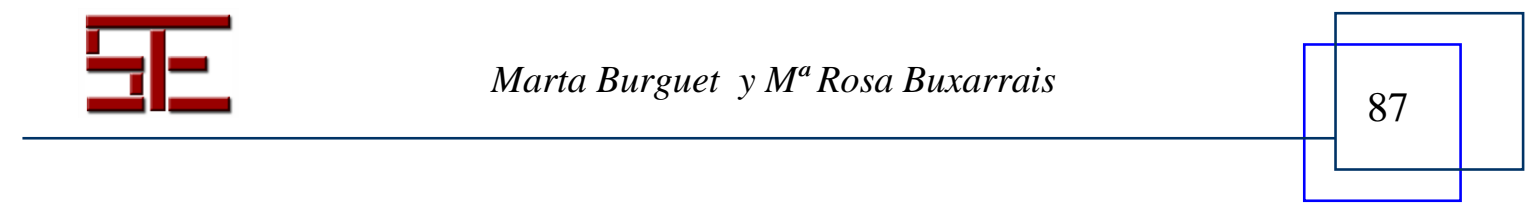




\section{THE ETHICS OF ICT. TRANSVERSAL COMPETENCIES AND PARADOX}

Abstract: Education systems in the era of new technologies have a revolution in traditional learning processes. For proper implementation of these changes, teachers have to be train in 'new' ethical competencies, which give meaning to the digital skills. This leads to a new way of understanding pedagogy where students gain prominence and autonomy to obtain, for themselves, answers to the questions. This kind of pedagogy implemented in the classrooms of both types of competency reveals some paradoxes that education must assume as current and future challenges.

Key words: ethical competence, digital competence; transversal competences; meaningful learning, meaning agencies. 


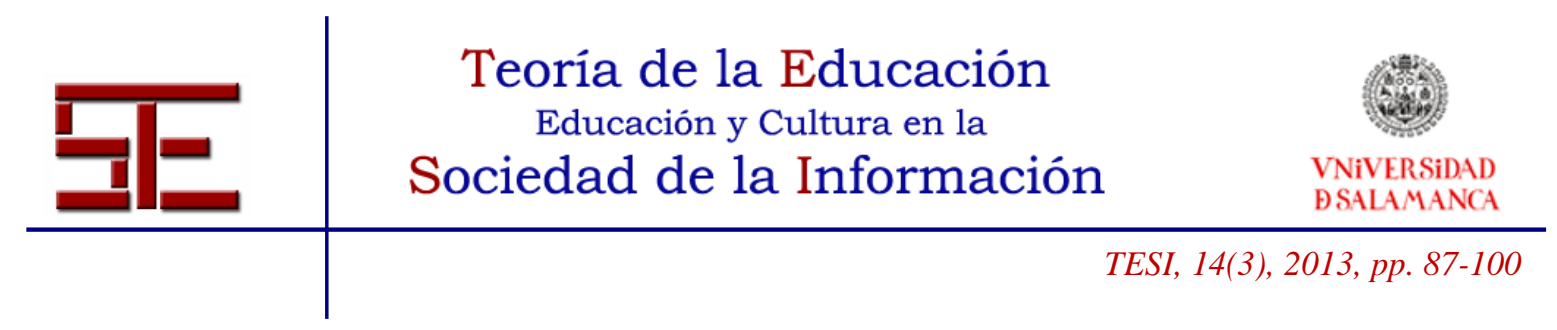

\title{
LA ETICIDAD DE LAS TIC. LAS COMPETENCIAS TRANSVERSALES Y SUS PARADOJAS
}

Fecha de recepción: 05/07/2013; fecha de aceptación: 05/09/2013; fecha de publicación: 30/11/2013

\author{
Marta Burguet \\ mburguetarfelis@ub.edu \\ Universitat de Barcelona \\ $\mathrm{M}^{\mathrm{a}}$ Rosa Buxarrais \\ mrbuxarrais@ub.edu \\ Universitat de Barcelona
}

\section{COMPETENCIAS PARA EDUCAR EN EL SIGLO XXI}

La sociedad actual, por las circunstancias que la caracterizan, se encuentra con nuevos retos a los que los docentes deben hacer frente en su tarea educativa. La educación en la era digital no se resuelve introduciendo los ordenadores en las aulas y facilitando el acceso a la ingente cantidad de información que circula por las redes, sino que entraña un nuevo modelo escolar que va más allá de la instrumentalización cibernética de los entornos educativos. Por ello, nuestra aportación se enmarca en todos los niveles educativos formales, desde la primaria hasta el nivel superior.

El profesor del siglo XXI adquiere carácter de facilitador, que fomenta el debate, la iniciativa y la atención a los estudiantes para que, con su supervisión y apoyo, vayan encontrando el camino hacia el conocimiento. El educador debe dar protagonismo al estudiante, promover la participación, priorizar el trabajo en equipo y la capacidad de debatir y solucionar conflictos de forma razonable y razonada. Más allá de ser un profesor autoritario que impone su ley, debe negociar las reglas con los estudiantes para que sean ciudadanos responsables (Buxarrais; Ovide 2011).

Se inscribe, así, en lo que se ha venido a denominar una pedagogía de la pregunta más que en una pedagogía de la respuesta que ha primado en nuestras aulas durante muchos siglos. Desde la pregunta, los estudiantes se sienten interpelados y ello les lleva a una nueva dimensión de su aprendizaje, en la que adquieren protagonismo y autonomía para obtener, por ellos mismos, respuestas a los interrogantes que su inherente curiosidad científica permite expresar. El afán de conocimiento nace de la pregunta, que emerge de la capacidad de sorprenderse ante el entorno y ante uno mismo. Sólo esa dimensión interrogativa puede garantizar un aprendizaje significativo.

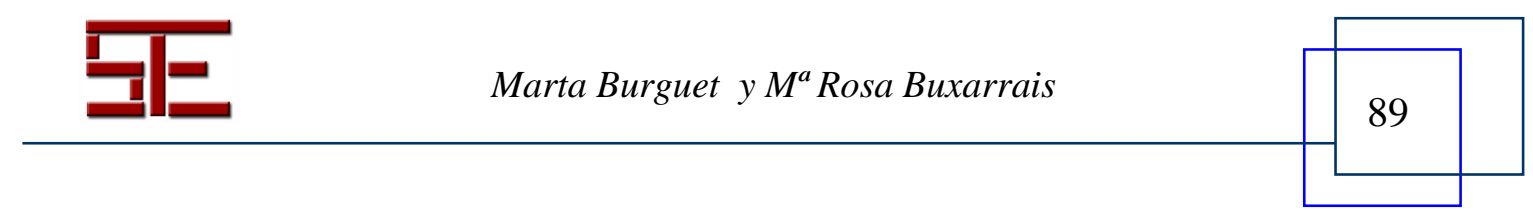




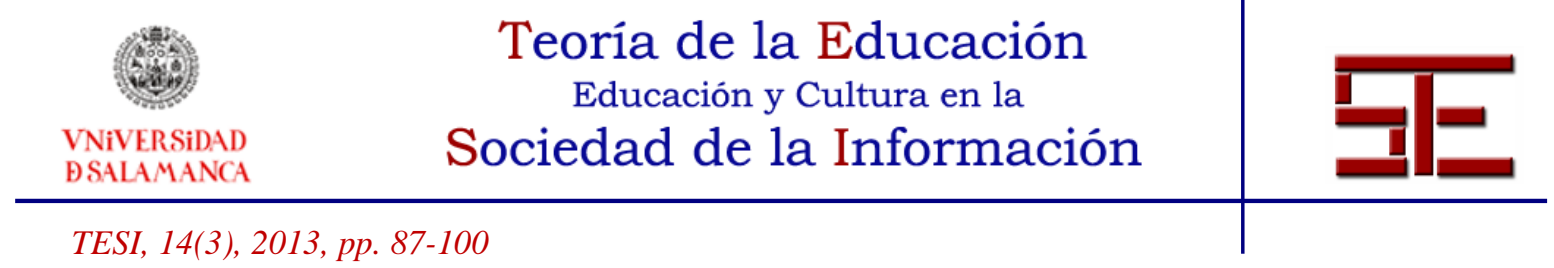

En la sociedad de la información y la comunicación se amplían los lenguajes y los soportes de manera que la construcción del conocimiento exige el manejo de múltiples disciplinas y habilidades, basándose todas ellas en esa capacidad de desarrollo autónomo hacia el conocimiento. Partiendo de los cuatro pilares de la educación para este siglo XXI que esboza Delors (1996), y en relación con las diferentes propuestas internacionales, en España se han definido ocho competencias básicas para la enseñanza obligatoria: 1) competencia en comunicación lingüística y audiovisual, 2) competencia artística y cultural, 3) competencia en el tratamiento de la información y digital, 4) competencia matemática, 5) competencia de aprender a aprender, 6) competencia de autonomía e iniciativa personal, 7) competencia en el conocimiento y la interacción con el mundo físico, 8) competencia social y ciudadana.

Entendemos por competencia la capacidad de responder con éxito a las exigencias personales y sociales que nos plantea una actividad o una tarea cualquiera en el contexto del ejercicio profesional. Sabemos que comporta dimensiones tanto de tipo cognitivo como no cognitivo. Así pues, una competencia es una especie de conocimiento complejo que siempre se ejerce en un contexto de una manera eficiente. Las tres grandes dimensiones que configuran una competencia son: saber (conocimientos), saber hacer (habilidades) y ser (actitudes) (Rué 2005).

En este sentido, cabe señalar aquí que la competencia comprende la capacidad de usar los conocimientos, habilidades y actitudes para que sean aplicados en el desarrollo de las tareas profesionales que competen. Además, la finalidad del Espacio Europeo de Educación Superior al evaluar por competencias (González; Wagener 2008, 25-33), no es otra que la de acercar el mundo laboral al académico, destacando así las experiencias de aprendizaje por encima de las experiencias de enseñanza.

Por ello, la adaptación de las titulaciones universitarias al nuevo contexto socioeconómico ha conllevado su diseño teniendo en cuenta los perfiles profesionales para los que estamos formando a los estudiantes y, en consecuencia, las competencias transversales, instrumentales y/o específicas- que deben desarrollarse a lo largo del proceso educativo. En el marco de estas competencias es donde podemos diseñar aquellas propias de los contextos digitales y vincularlas a las de carácter ético, cuya transversalidad podrá consolidar un aprendizaje desde la coherencia a implementar en los marcos de actuación profesional.

Por lo tanto, se requieren docentes formados en "viejas competencias" (Asensio 2012, 206) y "nuevas", para poder hacer frente al actual escenario educativo. Competencias que éstos deben adquirir en su formación inicial y, si no se diera el caso, en la formación continua. Dentro de las llamadas "nuevas competencias", en este artículo

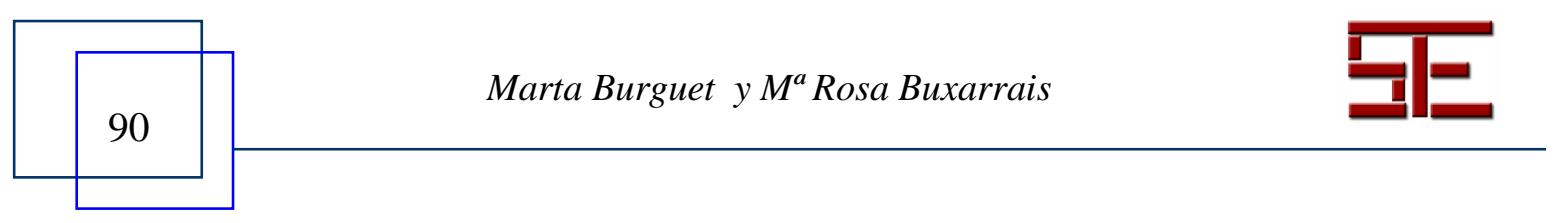




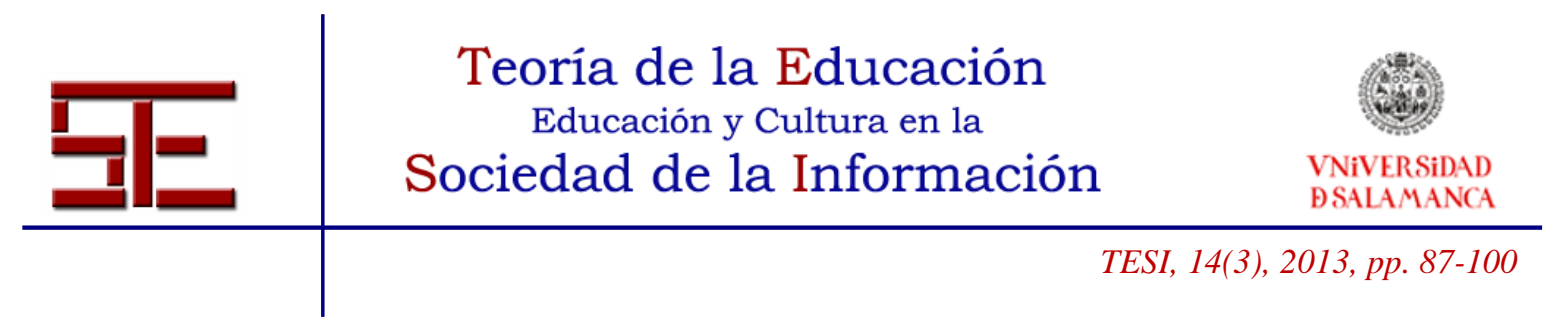

presentamos aquellas que por su carácter ético no han sido siempre consideradas anteriormente, y menos en relación a las competencias digitales.

Aquí centraremos nuestra atención en las competencias éticas (social y ciudadana) y las competencias digitales, dado el carácter indispensable que adquieren ante los retos educativos que nos ofrecen las nuevas tecnologías. Mientras el docente de antaño consolidaba su buen hacer profesional desarrollando la capacidad de adquirir conocimiento y transferirlo a sus educandos, el docente del siglo XXI debe mostrar competencias que le permitan incorporar el mundo digital en las aulas, y aquellas competencias que le habiliten para que su praxis comportamental mantenga coherencia con el proceder deliberativo teórico.

Por todo ello, y aun cuando centramos nuestro interés en el análisis de las competencias a adquirir por parte del profesional de la educación, no dejamos de hacer referencia a aquellas que los estudiantes deben consolidar en su aprendizaje. De hecho, en la formación de esos futuros profesionales de la educación se puede trabar esa progresividad de la adquisición de competencias precisas para su ejercicio profesional.

\subsection{Competencias éticas}

Aún sabiendo de la dificultad de evaluar las competencias éticas con indicadores objetivos, debemos afrontarlas, pues forman parte de la responsabilidad ética del docente. Así, será necesario que el docente disponga de conocimientos específicos para llevar a cabo dicha evaluación, principalmente a través de pautas de observación comportamental que permitan validar la coherencia de acción. Para ello, cabe potenciar la formación ética del profesorado, que actualmente está ausente en los planes curriculares de dichos profesionales en los diversos niveles educativos.

Hemos definido la competencia ética como el resultado del desarrollo de un conjunto de dimensiones de la personalidad moral, que experimenta la persona en situaciones de interacción social donde se plantea un conflicto moral, y que le ayuda a deliberar de forma justificada y actuar en coherencia, reconociendo en cada caso la globalidad de la situación y quiénes son los afectados. Por otro lado, significa implementar el respeto a la dignidad de la persona, su integridad y su individualidad.

La puesta en práctica de dicha competencia implica un análisis de la propia conducta, el interrogarse sobre las decisiones y actuaciones anteriores y trabajar sobre la propia persona, mediante la confrontación regular entre el origen y el sentido de las decisiones o actuaciones y los valores implícitos. De aquí que la competencia ética no es un

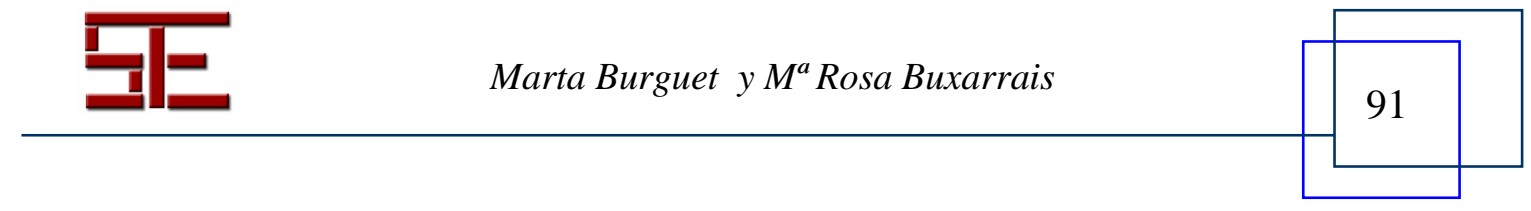




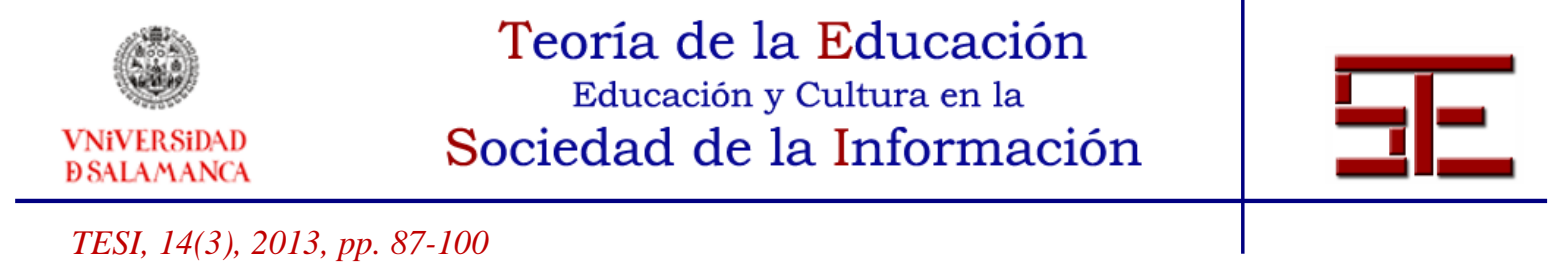

resultado acabado, sino un proceso, en el cual la autoevaluación es un procedimiento posible y coherente, que permite un diálogo constante con uno mismo y con el entorno.

Sin duda, nos referimos a un concepto sistémico de competencia ética porque debe tener en cuenta las interrelaciones que existen entre las diferentes dimensiones de la persona cognitivas, afectivas o emocionales y conductuales- que inciden en el desarrollo de la personalidad moral y contribuyen al aprendizaje ético. Sin embargo, como ya sabemos, es únicamente en el "actuar", o en la conducta, donde se expresan los valores tanto personales como profesionales, siendo las situaciones complejas una oportunidad para apreciar la coherencia y el compromiso con los valores construidos, gracias a la existencia de incertidumbres.

La competencia ética no es un resultado acabado, sino un proceso, un proceso donde la persona integra un conjunto de cualidades, habilidades y aptitudes adquiridas y transformadas a través del aprendizaje, que enlazadas con los valores y normas sociales le permiten actuar de manera eficaz y oportuna ante situaciones que generen cuestionamiento ético y que deban resolverse en los distintos ámbitos de la vida de la persona. En dicho proceso, la autoevaluación es el único procedimiento posible y coherente y, al mismo tiempo, es el punto de partida de nuevos desarrollos personales. Implica tanto la deliberación moral como la justificación ética, tanto asumir la historia personal pasada, con lo bueno y lo malo, como la conciencia del "querer ser" radical que orienta acciones presentes y otorga un sentido a las futuras. Se trata, pues, de un constructo dinámico en el cual están presenten toda una serie de habilidades cognitivas, emocionales, sociales y volitivas. Pero las decisiones y acciones que la hacen visible son consecuencia de un proceso de reflexión personal y no de un entrenamiento exterior sistemático.

Otro aspecto a tener en cuenta sobre la competencia ética es su ámbito de acción, es decir, el lugar de su incidencia. En este sentido, dicha competencia no se dirige a un ámbito específico de acción - personal, familiar, laboral y ciudadano- sino a todos en general, porque supone el hecho de poner atención por parte de cada uno a su propia persona -sensaciones, emociones, sentimientos, pensamientos- y el compromiso con su propio crecimiento, buscando, si su fuerza moral se lo permite, optar de modo autónomo y coherente en todos ellos, creando un estilo de vida propio.

En este sentido, y a pesar de que la mayor parte de los profesores universitarios manifiesta su acuerdo en que la formación universitaria debe contemplar la formación en competencia ética (Esteban y otros 2013), no se vislumbra cuando se planifica la actividad docente en las aulas, es decir, en los planes docentes y en el tipo de evaluación de los aprendizajes que se plantean. Por todo ello reafirmamos las carencias que se ponen de manifiesto en la formación ética de los profesionales de la educación.

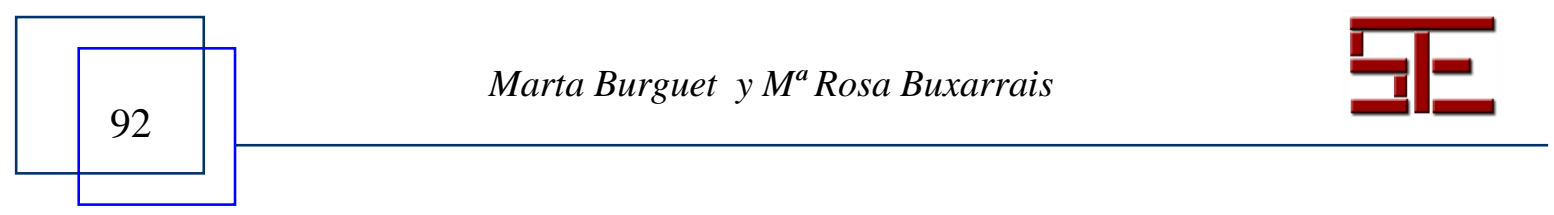




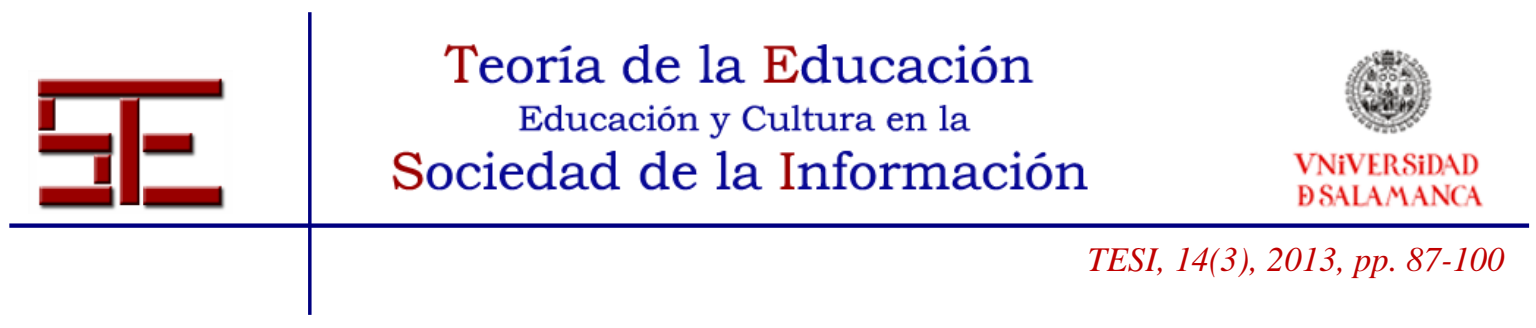

\subsection{Competencias digitales}

De ahí que los profesionales de la educación compartan la necesidad de una formación del profesorado también en competencias digitales (Aretio 2001), que se conciben como aquellas que incluyen habilidades en cuanto al manejo de las nuevas tecnologías, así como habilidades de acceso a la información y la transmisión de la misma, usando para ello distintos soportes e incluyendo la utilización de las tecnologías como elemento esencial (González y otros 2011).

Cabe aquí diferenciar entre información y conocimiento. Transformar información en conocimiento requiere la capacidad de procesar la información y razonarla para inferir, deducir y generar esquemas conceptuales de niveles de complejidad diversos que permiten interiorizar el saber -entendido como el elenco de conocimientos integrados- y elaborar pensamiento -como capacidad de procesar dicho saber y elaborarlo-. El acceso al conocimiento culmina con la capacidad de comunicarlo con diferentes lenguajes, formatos y medios. Pero el acceso al conocimiento no deviene inevitablemente en saber, sino que precisa de procesos de interiorización y reflexividad imprescindibles para que el conocimiento sea significativo y aporte sentido al vivir y hacer de los ciudadanos. Sólo así podrán surgir comunidades democráticas de saber y pensamiento plural más allá del mero conocimiento, que hayan integrado dichas áreas cognitivas a su vivir y seguir viviendo diarios. Con ello, el conocimiento adquiere significatividad y sentido.

Las herramientas digitales permiten al profesorado establecer nuevas formas y medios de aprender. Pero esta novedad, como forma, puede ir más allá de un mero cambio de metodología. Ahí es donde entran en juego la educación en valores y la adquisición de competencias éticas, que fomentan valores como la iniciativa personal, la solidaridad, el trabajo en equipo, la capacidad crítica y la capacidad de interacción social (Buxarrais; Ovide 2011). En la era digital, la eficacia del profesor se mide no sólo por la acumulación de conocimientos (los conocimientos tecnológicos del estudiante serán, casi sistemáticamente, mayores que los del profesor y la información sobre cualquier materia se podrá encontrar en la red), sino por disponer de habilidades pedagógicas que le permiten ayudar al estudiante a encontrar y seleccionar la información relevante y veraz, e identificar las fuentes fiables.

La habilidad de selección de la información -“el saber más valioso es saber qué es lo que no se necesita saber" (Innerarity 2011,32)- será valorada por encima de la habilidad de acumulación de conocimientos. La selección requiere competencias que la acumulación no precisa. Los criterios de selección vienen determinados por los niveles de significatividad que cada quien otorga a cuánto conoce, criterios de discriminación inteligente a modo de filtros: "La mente sintetizadora es capaz de partir de una copiosa

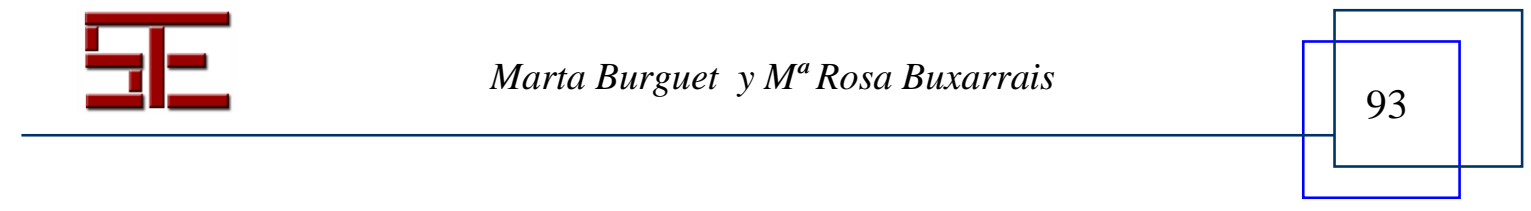




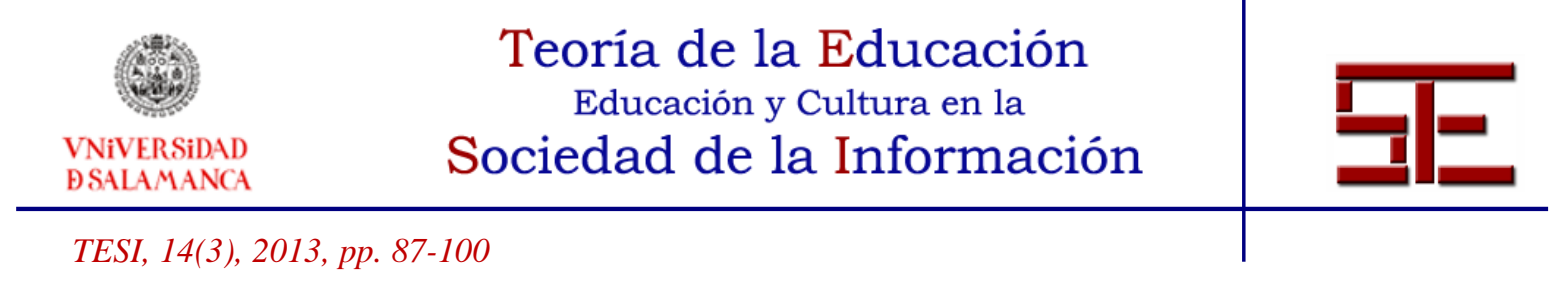

información, aplicar criterios fiables para determinar lo que interesa y lo que no, reordenar las cosas para que sean manejables..." (Gardner 2011, 197). De tal modo que la información adquiera significado y provoque procesos de creación y construcción de pensamiento, ya sea de modo constructivo o por conectivismo (Siemens 2010).

Esta construcción de pensamiento adquiere importancia primordial en la era digital, cuando la creación del mismo es competencia de cualquier ciudadano que tenga acceso a ese espacio virtual de representatividad, pero cuya construcción va más allá de la mera democratización del saber compartido. Si la creación y difusión de conocimiento queda garantizada de modo digital a través de los espacios virtuales de saber compartido, la construcción del mismo, a través de conectores neuronales que mantienen en constante evolución dicho pensamiento, supone un nivel mayor en el que los espacios mentales se interrelacionen de modo activo y permitan pensar y repensar constantemente el saber, nunca suficientemente establecido y en permanente evolución y cambio.

No en vano, Kaplún (2006) habla del impacto pedagógico que las nuevas tecnologías tienen en los procesos de enseñanza y aprendizaje, centrando la atención en el análisis de los aportes positivos que se derivan. Ahí es donde la educación puede garantizar el gran salto de la educación bancaria (Freire 1997) al diálogo de saberes en construcción y evolución permanente.

A su vez, en la adquisición de competencias digitales, será de vital importancia recuperar los aportes de Dewey a través del pragmatismo pedagógico, sabiendo que aprender haciendo será la clave para la consolidación de competencias digitales, más allá de su mera adquisición: "el conocimiento del curso natural del desarrollo siempre se vale de situaciones que implican aprender por medio de una actividad, aprender haciendo" (Dewey 1967, 95).

En definitiva, la formación del profesorado sobre dicha competencia supone una práctica que acredite los conocimientos. No puede quedar recluida meramente en unos conocimientos previos del mundo online y las diferentes herramientas o soportes, que deben ser proporcionados en los diferentes niveles de su formación (profesorado de primaria y secundaria), si no se han contemplado en los diversos planes de estudios.

\section{TRANSVERSALIDAD ÉTICO-DIGITAL: ETICIDAD DE LA DIGITALIDAD}

Viendo la necesaria capacitación en competencias de carácter ético y de carácter digital, constatamos la interrelación y transversalidad de ambas tipologías, que queda patente a través de los elementos éticos que marcan un determinado modo la digitalidad.

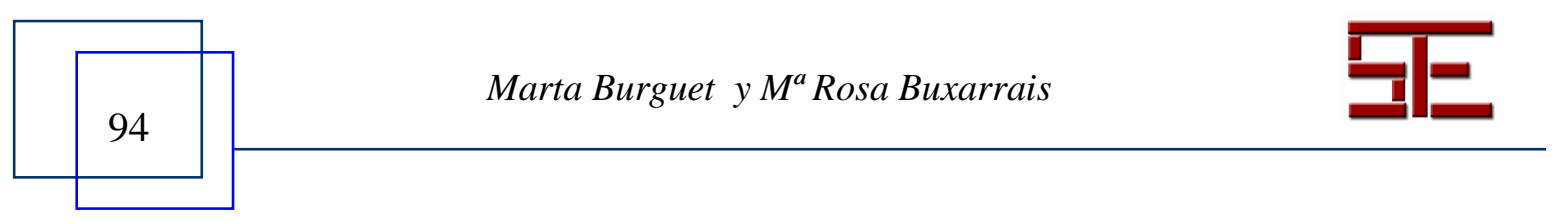




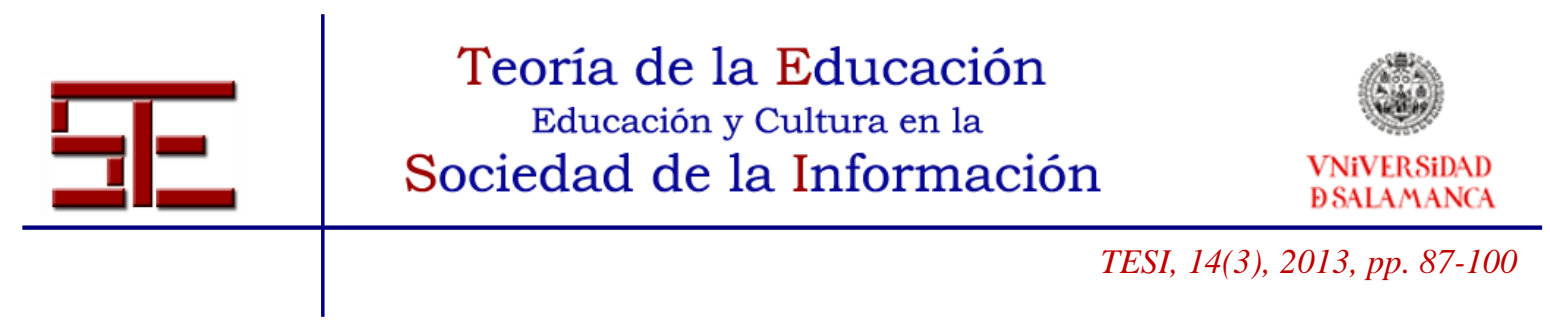

Así, acudimos a lo que consideramos en denominar "agencias de sentido" como esos entes que dotan de criterios éticos para otorgar significado al conocimiento $y$ seleccionarlo en función de la significatividad que adquiera para cada persona. Cabe señalar que no las entendemos como agencias que seleccionan la información adecuada y desean dotar al usuario de aquel saber que consideran válido, alejándole de adquirir la competencia de desarrollo autónomo. Por el contrario, como "agencias de sentido" entendemos aquellos entes que contribuyen a la democratización del pensamiento desde criterios de sentido autónomos y responsables, ya que el pensamiento se construye por procesos de internalización del saber y de dotación de sentido del mismo; una información que viene dotada de sentido por los procesos de reflexividad, que imbrican la digitalidad y la ética, considerando la necesidad de espacios y tiempos de reflexividad, que aporten sentido a los saberes acumulados y contribuyan así a su selección. Nos referimos a unas agencias que no sólo dan sentido a la información para construir pensamiento autónomo y saber, sino que permiten crear sentido y construirlo, más allá del mero otorgar sentido.

De algún modo, estas agencias permiten diseñar horizontes de sentido a la digitalidad. Para elaborar pensamiento es de vital importancia el vínculo que se establece con el conocimiento. Por ello, a mayor vínculo, más significatividad y mayor sentido para la construcción de saber. De ahí que las capacidades éticas en las que formar a los profesionales de la educación deben garantizar el desarrollo de la autonomía del educando, para que la construcción de su pensamiento permita ir más allá del 'corta y pega' tan propio de la digitalidad, y superar el plagio narrativo que lleva a vidas parasitarias vacías de sentido. Con ello, las "agencias de sentido" construyen ciudadanos con pensamiento propio, que puede emerger de los espacios y tiempos de reflexividad debidamente contrastada, a menudo con horizontes de sentido a contra corriente del común de los sentires. Por ello, la garantía del contraste puede contribuir a que aquellos espacios de reflexividad personal no se erijan en categoría de verdad absoluta si no es pasando por el necesario diálogo y debate de pensares individuales debidamente contrastados, para que surja ese pensar compartido.

Como capacidades generadoras de sentido en la construcción del pensamiento podemos destacar la capacidad de curiosidad y sorpresa (L'Ecuyer, 2012), ese afán por descubrir aquello que interpela del entorno, y con ello el necesario afán por la pregunta, origen de toda aproximación al conocimiento. Con esta habilidad por despertar curiosidad, no podemos olvidar la capacidad también de cuestionar los saberes consolidados, de romper reglas generalizadas y comúnmente aceptadas, liberalizando el pensamiento y aceptando la mutabilidad de ciertas verdades. Aparecen también como competencias transversales el desarrollo de nuevos tipos de interacción, no convencionales, de todos con todos -relaciones 2.0-, en las que generar relaciones de confianza y autoconfianza

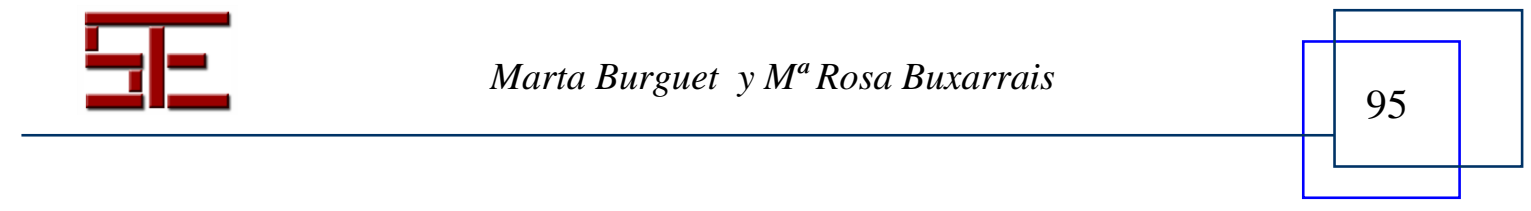




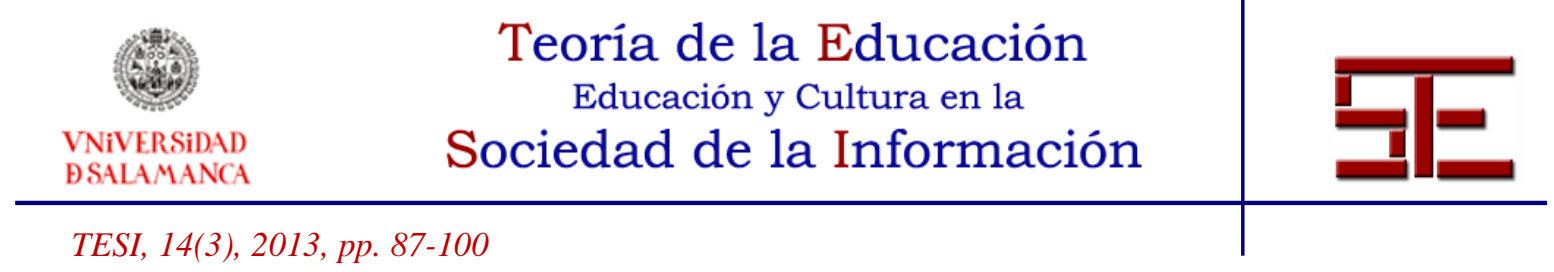

será clave para sobrevivir en la red de modo autónomo, proactivo y participativo, desarrollando nuevas habilidades dialógicas sociales, de tipo presencial y digital.

Al fin y al cabo, el mayor reto de este sustancial cambio educativo será formar ciudadanos autónomos y críticos, responsables de la gestión de su pensar y saber, compartiendo responsabilidad a través de la gestión propia y compartida de un uso ético del mundo digital, sabiéndose co-constructores del saber y pensar, así como del actuar, sentir y vivir juntos. Con ello, formar ciudadanía en competencias ético-digitales supone apostar por la construcción de ciudadanos libres cuya base antropológica se construye a partir de la apuesta por la libertad humana, desde un saber experiencial (basado en el desarrollo de las ciencias positivo-experimentales) hacia un saber vivencial (arraigado en el cúmulo de experiencias).

\section{PARADOJAS Y NUEVAS ALERTAS}

Los rasgos señalados como constitutivos de la sociedad educativa y del conocimiento del siglo XXI conllevan ciertas paradojas, algunas de las cuales señalamos a continuación, a modo de singularidades y contradicciones internas:

\subsection{Seguridad versus incertidumbre}

Entre el saber experiencial y vivencial que caracteriza el cúmulo de competencias adecuadas para vivir en las sociedades urbanas, digitales y occidentales del siglo XXI, cabe destacar la capacidad de convivir armónicamente con márgenes amplios de inseguridad e incertidumbre. Esta capacidad se presenta como paradoja versus la necesidad de permanente seguridad, que ha puesto de relieve la ingente proliferación de agencias de seguros en todos los ámbitos.

Dado que se considera conocimiento todo aquello que es verdadero pero variable en el tiempo, la incertidumbre de esas verdades mutantes incrementa los niveles de angustia en los que el ciudadano del siglo XXI debe aprender a convivir. Si bien el conocimiento único que de modo enciclopédico presentaban las sociedades medievales otorgaba verdades seguras también en el ámbito del conocimiento, la democratización del saber que ha abierto sus puertas a través de las redes internautas ha incrementado los márgenes de indeterminación, confiriendo a la ciudadanía mayor protagonismo a la vez que vértigo ante tal protagonismo del propio hacer y hacerse.

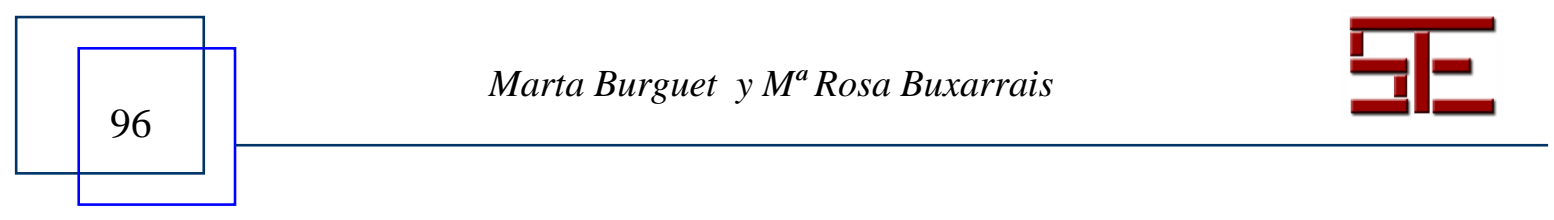




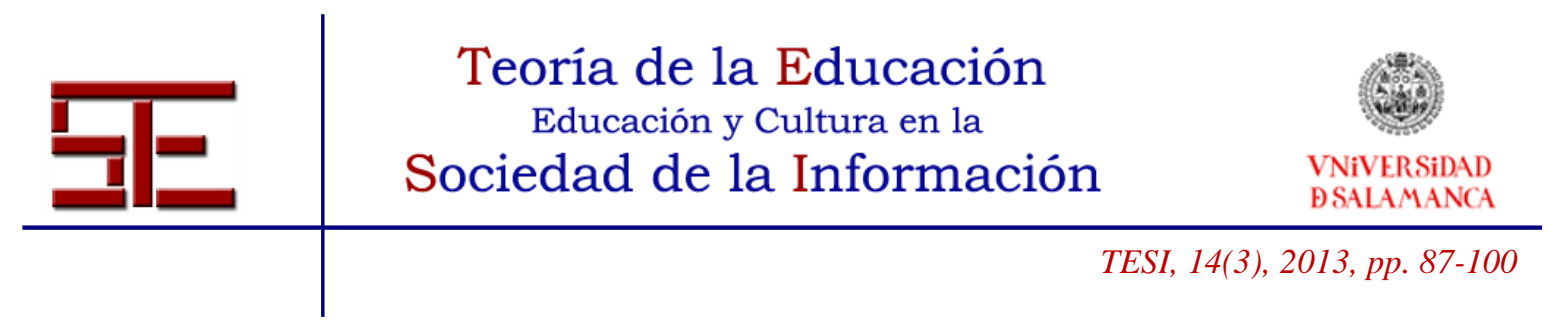

\subsection{Conductivismo versus constructivismo}

Si bien las nuevas tecnologías garantizan nuestra conexión en una red cada vez más amplia, este tejido de conexión no siempre va unido a mayor conocimiento entre los diversos puntos de la red. Mayor conectividad no es garante de mayor conocimiento, ni del conocimiento como competencia lógica, ni del conocer y conocerse entre los diversos usuarios de la red. Las relaciones se establecen de modo mucho más amplio, pero también con mayor superficialidad y liquidez.

De igual modo, el conocimiento conectivo, combinado a partir de nuevas ideas entrelazadas (Siemens 2010) -desarrollo de una inteligencia colectiva creciente-, implica el reconocimiento de validez de todo interlocutor con carácter de fiabilidad en el proceso de deliberación público para la construcción de saber, pero no comporta sus paradojas. Esta construcción del conocimiento conlleva dicotomías al considerar los indicadores de validez de los interlocutores, ya sea por criterios de universalidad o, por contrapartida, por criterios de validez de la construcción intrínseca del saber de dichos interlocutores. No es su validez como personas la que entra en cuestión, sino la validez argumentativa y/o explicativa del proceso de construcción de pensamiento que hayan establecido, en esa democratización del pensamiento, conocimiento y saber. Nos preguntamos ahí quién establece esos indicadores y qué agencias, que podemos denominar "agencias de sentido", indicarán su validez.

\subsection{Indiferencia versus asombro}

El mundo digital, medido y pautado desde la diada en clave 0-1, parece que no tiene espacio para la sorpresa. Ante el clic de un botón, la consecuencia es evidente y no da lugar al asombro, pues consecuentemente debe aparecer aquello que se ha clicado. Si nuestros adolescentes viven inmersos en su propia indiferencia hacia todo cuanto les rodea, la digitalidad puede llevarlos a una mayor inmersión en ese mundo de lo previsto, esperado y que por consiguiente no da lugar a ninguna imprevisibilidad.

Estas competencias en las que debe capacitarse el profesor del siglo XXI suponen una nueva dicotomía, entre la hegemonía del saber lógico-secuencial y la hegemonía del saber orientado por la belleza y la bondad, cuya inmersión requiere de una aproximación desde el asombro y el desarrollo de la capacidad intuitiva. Así es como habrá que capacitar al educador para que pueda adquirir competencias éticas que desarrollen la capacidad de perplejidad y asombro por lo que nos rodea, percibiendo la belleza y con apertura a lo inesperado e imperceptible.

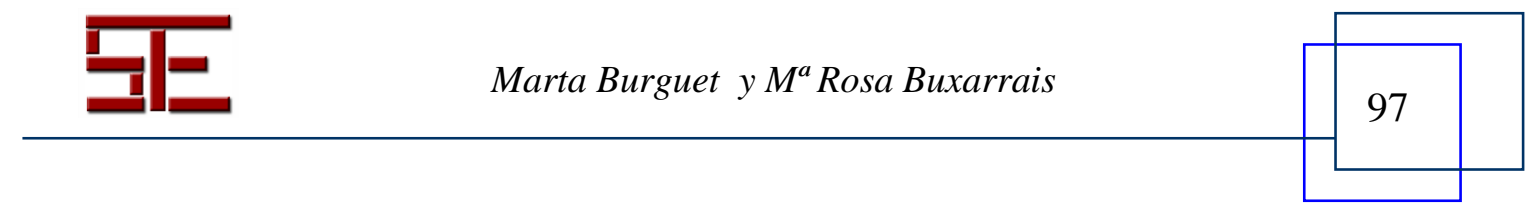




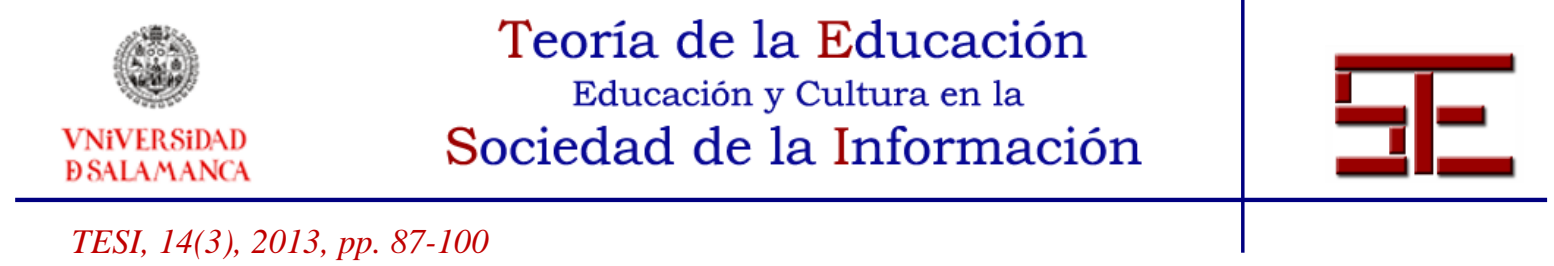

\subsection{Inmediatez versus reflexividad}

La discontinuidad temporal en los intercambios a través de la red permite ampliar los procesos de reflexión, que un diálogo presencial a menudo no posibilita, ya que requiere de mayor prontitud de respuesta comunicativa. Sin embargo, aparece también la inmediatez comunicativa de la red con la proliferación de mensajes virtuales que casi exigen una respuesta al instante. Si bien el aula virtual permite asincronía temporal y con ello mayor tiempo de respuesta, con lo que puede potenciarse la reflexividad, también las redes sociales actuales aceleran el ritmo en la creación, acumulación y depreciación del conocimiento, que en un espacio de tiempo más acotado pasa de ser significativo a ser caduco.

Aparece aquí el valor del tiempo y el retorno al aprendizaje lento que permite consolidar y sedimentar lo adquirido, de tal modo que se retiene en el poso más interno del conocimiento para afianzarlo como aprendizaje significativo. De ahí la importancia cada vez más relevante de la gestión del tiempo, como competencia ética a adquirir por parte del educador. El aprendizaje a base de pantallazos a menudo impide conciliar el tiempo digital con el tiempo y ritmo necesario para el aprendizaje. Un tiempo que maneje la propia persona y que no quede diluido en los tiempos de los otros, cuya realidad temporal requiere también de su propia gestión. Como seres espaciotemporales que somos, la configuración humana viene determinada por ambas variables, pero no por ello ingestionables.

\subsection{Magistrocentrismo versus pantocentrismo}

Las aulas de antaño centraban su infraestructura arquitectónica en relevar el papel del maestro desde la potenciación de las tarimas, orientando todos los alumnos alrededor del maestro, tanto en su ubicación espacial como en la misma concepción educativa. Nuestras aulas del siglo XXI orientan su ubicación hacia la pantalla, de tal modo que el maestro puede estar incluso ausente del aula. Por extensión, también los espacios educativos no formales e informales orientan la visión hacia la pantalla, ya sea en los mismos transportes públicos, estaciones de transporte, esperas de la atención médica, hogares... El protagonismo educativo ha pasado a manos de la digitalidad, con la pantalla como nueva protagonista.

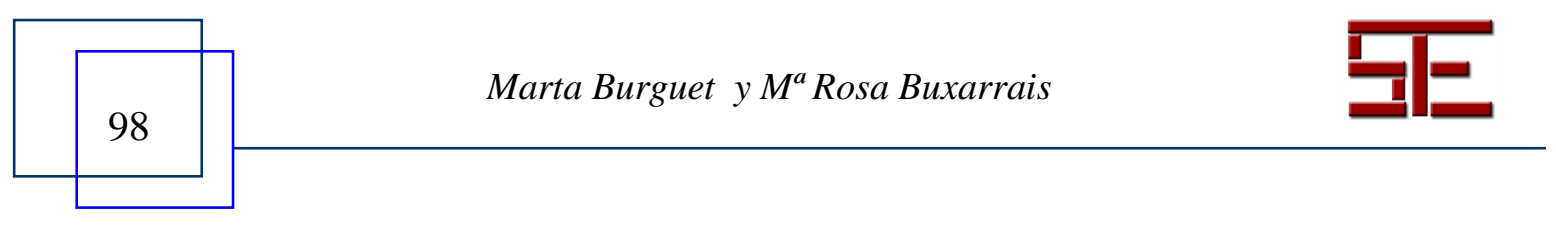




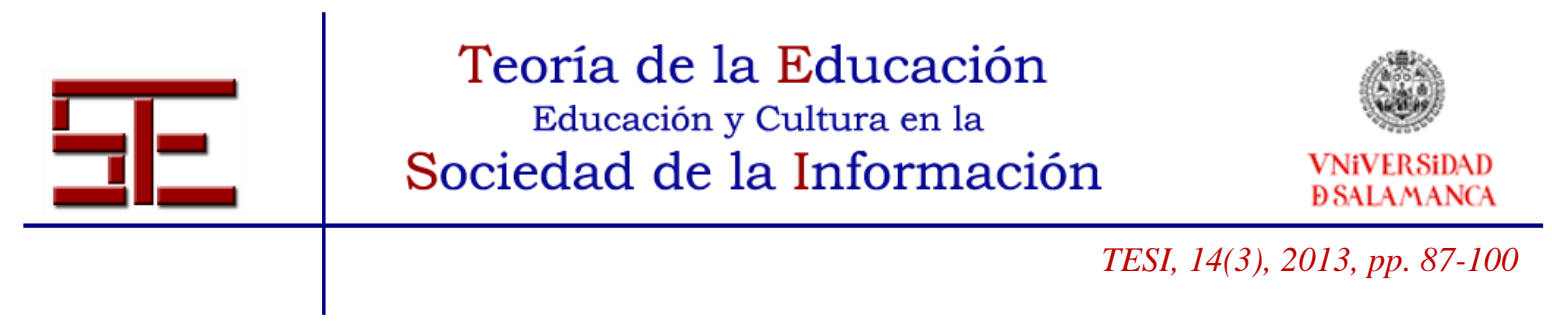

\section{REFERENCIAS}

Asensio (coord.) (2012). Las competencias de los profesionales de la educación hoy. La transformación de la práctica educativa. En García Aretio, L. (ed.), Sociedad del conocimiento y Educación (pp. 193-213). Madrid: UNED.

Buxarrais, M.,Ovide, E. (julio - diciembre, 2011). El impacto de las nuevas tecnologías en la educación en valores del siglo XXI. Sinéctica, 37. Extraído el 1 Septiembre de 2013, de

http://www.sinectica.iteso.mx/?seccion=articulo\&lang=es\&id=520_el_impacto_d e_las_nuevas_tecnologias_en_la_educacion_en_valores_del_siglo_xxi http://www.sinectica.iteso.mx/?seccion=articulo\&lang=es\&id=520_el_impacto_d e_las_nuevas_tecnologias_en_la_educacion_en_valores

Cabrera, N. y Burguet, M. (2012). Evaluando competencias en entornos virtuales a través del trabajo final de máster. Dídac, 60, 20-26.

Delors, J. (1996). La educación encierra un tesoro. Madrid: Santillana/Unesco.

Dewey, J. (1967). Democracy and education. New York: The free Press.

Esteban, F., Buxarrais, M.R. y Mellen, T. (2013). What do University Teachers Think aout the Teaching in Ethics and Citizenship in the European Higher Education Area? The New Educational Review, 32, 2. Extraído el 1 Septiembre de 2013, de http://www.educationalrev.us.edu.pl/vol/tner_2_2013.pdf

Freire, P. (1997). Pedagogía de la autonomía. México: Siglo XXI.

Fullat, O. (2002). Pedagogía existencialista y postmoderna. Madrid: Síntesis.

Gardner, H. (2011). Verdad, belleza y bondad reformuladas. Las virtudes del siglo XXI. Barcelona: Paidós.

García Aretio, L. (2001). Formación a distancia para el nuevo milenio. ¿Cambios radicales o de procedimiento? En On-Line-EDUCA. Madrid: Universidad Nacional Abierta. Extraído el 1 Septiembre de 2013, de Fuente: http://prometeo.cica.es/teleformacion/

González, A., y otros (2011). El aprendizaje por competencias en la educación obligatoria. Valencia: Brief Ediciones.

González, J. y Wagener, R. (eds.) (2008). La contribución de las Universidades al proceso de Bolonia - Una introducción. Bilbao: Universidad de Deusto.

Innerarity, D. (2011). La democracia del conocimiento. Por una sociedad inteligente. Barcelona: Paidós.

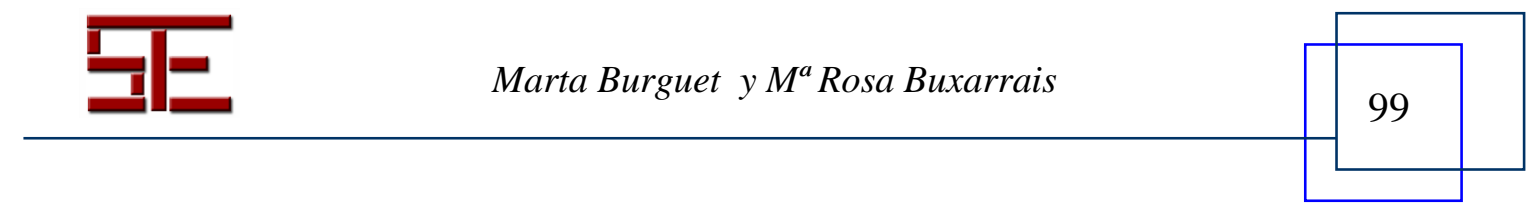




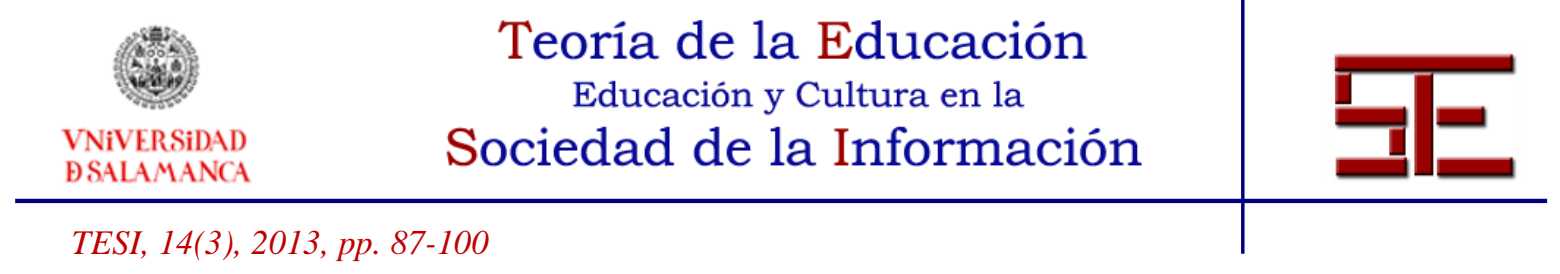

Kaplún, G. (2006, sept-dic. 3, 49-60). ¿Democratización electrónica o neoautoritarismo pedagógico? Revista de Economía Política de las Tecnologías de la Información y Comunicación. Extraído el 1 Septiembre 2013, de http://www.eptic.com.br/site/revista-eptic-online-volume-viii-numero-3setembro-dezembro-de-2006/

L'Ecuye, C. (2012). Educar en el asombro. Barcelona: Plataforma.

Rué, J. y Martínez, M. (2005). Les titulacions UAB en l'Espai Europeu d'Educació Superior. Cerdanyola del Vallès: IDES-UAB.

Siemens, G. (2010). Conociendo el conocimiento. Ediciones Nodos Ele. Extraído el 15 Junio, 2013, de http://www.nodosele.com/editorial/indice/

Para citar el presente artículo puede utilizar la siguiente referencia:

Burguet, M. y Buxarrais, M. R. (2013). La eticidad de las TIC. Las competencias transversales y sus paradojas. Revista Teoría de la Educación: Educación y Cultura en la Sociedad de la Información. 14(3), 87-100 [Fecha de consulta: dd/mm/aaaa].

http://campus.usal.es/ revistas_trabajo/index.php/revistatesi/article/view/11352/11782

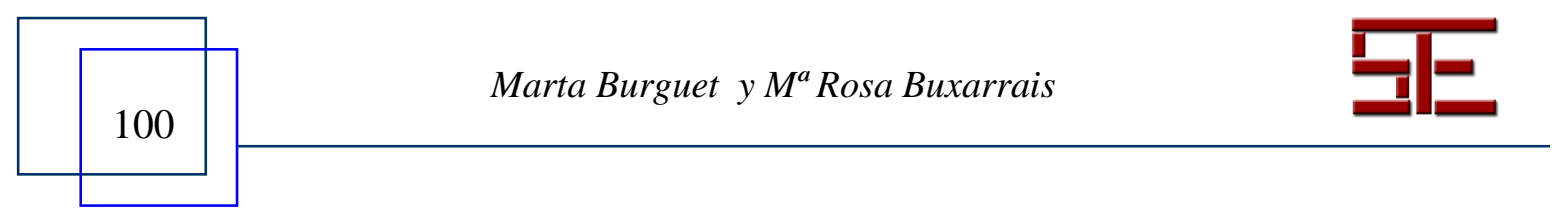

